\title{
População, desenvolvimento e sustentabilidade: perspectivas para a CIPD pós-2014
}

\author{
José Eustáquio Diniz Alves*
}

A Conferência Internacional sobre População e Desenvolvimento (CIPD), ocorrida em 1994, na cidade do Cairo, completa 20 anos. A Assembleia Geral das Nações Unidas (UNGASS) apresentará propostas de ampliação e continuidade do Programa de Ação da CIPD para além de 2014. Em 2015 termina o prazo de 15 anos dos Objetivos do Desenvolvimento do Milênio (ODM), que devem ser substituídos pelos Objetivos do Desenvolvimento Sustentável (ODS), proposta aprovada na Conferência das Nações Unidas sobre Desenvolvimento Sustentável, a chamada Rio+20, realizada em 2012, na cidade do Rio de Janeiro.

Estabelecer uma proposta de ação global para o período 2015 a 2030, reunindo temas sobre população, desenvolvimento e meio ambiente, pode representar um ganho significativo. No passado, a ONU, pressionada pelas divergências geopolíticas da Guerra Fria, seccionou estes três temas ao realizar a Conferência sobre Meio Ambiente Humano em Estocolmo (1972) e a Conferência Mundial de População em Bucareste (1974). Nas Conferências seguintes a divisão se manteve. Se tal estratégia, por um lado, facilitou a aprovação de resoluções específicas, por outro, dificultou o tratamento conjunto das questões relativas a população, economia e ambiente.

Para aprofundar esse debate na comunidade demográfica, a Associação Latino-Americana de População (Alap) e a Associação Brasileira de Estudos Populacionais (Abep), com o apoio de diversas instituições, organizaram o seminário internacional "CIPD para além de 2014 e a dinâmica demográfica da América Latina e Caribe”, entre 15 e 17 de julho de 2013, nas dependências do IBGE, no Rio de Janeiro. Este evento também serviu como preparação para a incidência da sociedade civil na Primeira Reunião da Conferência Regional de População e Desenvolvimento (CRPD) de Montevidéu, ocorrida de 12 a 15 de agosto de 2013, na qual foi aprovado o documento "Consenso de Montevidéu".

\footnotetext{
*Escola Nacional de Ciências Estatísticas - Ence, do Instituto Brasileiro de Geografia e Estatística - IBGE, Rio de Janeiro-RJ, Brasil, (jose.diniz@ibge.gov.br).
} 
No último número da Revista Brasileira de Estudos de População - Rebep, a demógrafa Ana Amélia Camarano, que esteve no seminário do Rio, contribuiu com a discussão apresentando um artigo, na seção de Ponto de Vista, denominado "Perspectivas para o Cairo+20: como avançar na discussão sobre população e desenvolvimento". O texto tem o mérito de ser transparente e objetivo, o que contribui para o debate acadêmico.

A ciência avança por meio de conjecturas e refutações. Neste sentido, o objetivo do presente texto é dar continuidade à discussão ocorrida no seminário da Alap/Abep, por um lado, apresentando uma visão crítica ao processo de revisão do Cairo+20 e, em especial, aos resultados da 47a Reunião da Comissão de População e Desenvolvimento (CPD) da ONU, ocorrida em abril de 2014, e, por outro, dialogando com o artigo citado (CAMARANO, 2013), com o intuito de contribuir para o aprofundamento da discussão sobre população e desenvolvimento sustentável.

\section{População e desenvolvimento}

O debate sobre população e desenvolvimento teve início antes dos escritos de Thomas Malthus e começou de forma otimista, impulsionado pelas esperanças iluministas que apostavam todas as suas fichas no progresso (ou, nos termos atuais, desenvolvimento). Considerado o grande mentor da ciência econômica moderna, Adam Smith escreveu em 1776, na sua obra que explica como as nações ficam ricas, que "O marco mais decisivo da prosperidade de qualquer país é o aumento no número de seus habitantes” (SMITH, 1983, p. 56).

Esta visão positiva do crescimento populacional fez parte do pensamento político do iluminismo e da economia clássica. Pensadores como o marquês de Condorcet e William Godwin - precursores do pensamento demográfico - tinham uma visão favorável do crescimento econômico e populacional. David Ricardo, influente economista inglês do início do século XIX, também via com bons olhos o crescimento demoeconômico, considerando o desenvolvimento uma variável independente e a população uma variável dependente.

Neste debate ocorrido no início da modernidade, a grande voz destoante veio de um pastor da Igreja Anglicana, que representava os interesses dos proprietários de terra contra os interesses dos trabalhadores e da burguesia nascente e defendia os princípios do antigo regime monárquico (aristocracia absolutista) contra a República e o Estado de Direito. Thomas Malthus formulou uma suposta lei de população para argumentar que a humanidade jamais seria capaz de promover o desenvolvimento econômico, reduzir a pobreza e as taxas de mortalidade e aumentar a qualidade de vida das pessoas. Para Malthus, o desenvolvimento econômico seria inviável historicamente, pois a população, sendo uma variável independente, tendia a crescer sempre acima da disponibilidade dos meios de subsistência, o que inviabilizaria qualquer tipo de progresso social.

Ao contrário de Malthus, o representante máximo do pensamento socialista, Karl Marx, considerava que o capitalismo é sempre capaz de produzir bens e serviços em progressão 
superior ao crescimento demográfico. O excesso de população não seria nada mais do que uma estratégia criada (pela mudança da composição orgânica do capital) para produzir uma "superpopulação relativa” ou um "exército industrial de reserva”, com o objetivo de manter um estoque humano de pessoas destituídas dos meios de produção à disposição da burguesia industrial. Para o marxismo, a população é uma variável neutra e a acumulação capitalista (desenvolvimento) a variável independente.

Este breve panorama do embate ocorrido nos séculos XVIII e XIX serve para situar a retomada do debate no século XX, quando surgiu um fenômeno novo: a transição demográfica. Nostestein (1945) foi um dos primeiros autores a confirmarem a intuição de Condorcet e Godwin de que o progresso (processo de modernização) traria incremento no padrão de vida da população e avanços da medicina, possibilitando a redução das taxas de mortalidade. Mas ele foi além, mostrando que, após um certo lapso de tempo, as taxas de fecundidade também se reduziriam com a modernização econômica e social. Novamente o desenvolvimento é visto como uma variável independente e a população como uma variável dependente.

Porém, o influente livro População e desenvolvimento econômico, de Ansley Coale e Edgard Hoover (1966), publicado originalmente em 1958, argumenta que a experiência da transição demográfica seria diferente entre os países do Primeiro Mundo e os do Terceiro Mundo. No primeiro caso, a transição ocorreria tal como descrita pelo arcabouço da teoria da modernização. Mas, no segundo, a queda da mortalidade teria se dado de forma exógena e sem grandes transformações da estrutura econômica dos países subdesenvolvidos. Porém, como os países de baixa renda ainda estavam atrasados no processo de desenvolvimento e na mudança da estrutura social, tenderiam a prevalecer as "escoras culturais pró-natalistas", que sustentam um maior tamanho de família. Sem a transição da fecundidade, os países do Terceiro Mundo cairiam no círculo vicioso da "armadilha da pobreza”. Nesse caso, altas taxas de crescimento demográfico seriam responsáveis pelo atraso econômico e o crescimento populacional seria uma variável independente.

Foi neste contexto que surgiram as correntes neomalthusianas mais atuantes. Seus adeptos, ao contrário de Malthus, defendiam a estabilidade populacional não pelo aumento das taxas de mortalidade, mas sim pela redução das taxas de fecundidade. Eles consideravam que a redução do ritmo de crescimento da população seria essencial para o "take off" (decolagem) do desenvolvimento, pois não poderia haver incremento da renda per capita sem a redução do ritmo de crescimento do denominador da equação e sem a diminuição do ônus da razão de dependência dos jovens.

Na década de 1970, a transição da fecundidade deixou de ser uma possibilidade para se tornar uma realidade em uma extensa gama de países, de diferentes níveis de desenvolvimento. Para Caldwell (1982), a chave para se entender o processo de transição da fecundidade estaria na compreensão da magnitude e direção do fluxo intergeracional de riqueza, processo que tem certa autonomia em relação aos indicadores econômicos. 0 próprio Coale (1979), com base nos estudos da Universidade de Princeton, reavaliou os 
processos de transição demográfica e abandonou a ideia da necessidade de um "limiar de desenvolvimento" para o início da redução do número médio de filhos.

O desenvolvimento passa a ser visto como uma condição suficiente, mas não necessária à transição da fecundidade. Ampliou-se, portanto, o leque de interpretações, sendo que a população continuou sendo tratada como "solução" por alguns e como "problema" por outros (COHEN, 2012). Todavia, a ideia de progresso e a defesa apologética do desenvolvimento (capitalista ou socialista) sempre ocorreram de forma geral e irrestrita, com base no mito da excepcionalidade humana e do avanço civilizatório.

\section{As conferências sobre população e desenvolvimento}

O debate acadêmico não acontece no vácuo e sempre influi e é influenciado pelo ambiente político internacional. Após os acordos de Bretton Woods e os acertos políticos ocorridos no final da Segunda Guerra Mundial, houve uma reconfiguração do arcabouço da governança mundial com a criação de instituições nas áreas política (ONU), financeira (FMI), econômica (Banco Mundial), comercial (GATT), etc. Foi nesta nova institucionalidade e em um quadro de crescimento econômico excepcional que surgiram e se ampliaram as conferências sobre população, desenvolvimento e meio ambiente.

As duas primeiras conferências internacionais sobre população - Roma, 1954, e Belgrado, 1965 - tiveram um perfil acadêmico, sem caráter oficial. A primeira Conferência sobre População organizada pela ONU e com a presença de delegações oficiais aconteceu em Bucareste, em 1974. Evidentemente, os embates e as concepções de mundo, relatados no item anterior, estavam presentes nesta Conferência.

De forma um tanto esquemática, é possível afirmar que a Conferência de 1974 ficou dividida entre os "controlistas" e os "desenvolvimentistas". No contexto da Guerra Fria, os países capitalistas mais ricos, capitaneados pelos Estados Unidos, defendiam a concepção neomalthusiana de reduzir a fecundidade para promover o desenvolvimento e a erradicação da pobreza. Mas a União Soviética e os países do Terceiro Mundo, liderados pela China e pela Índia, defendiam a prioridade do fortalecimento das políticas de apoio ao desenvolvimento em contraposição ao controle da natalidade e ao planejamento familiar. Venceram os segundos, com o bordão símbolo de Bucareste: "O desenvolvimento é o melhor contraceptivo". Como afirmou Berquó (2014, p. 19): “O Plano de Ação da Conferência não propôs metas temporais explícitas para as taxas de crescimento populacional”.

Mas antes mesmo da Conferência Internacional de População do México, em 1984, houve uma surpreendente reconfiguração do jogo de forças políticas. A China comunista, que liderou o combate ao neomalthusianismo em Bucareste, passou a adotar, a partir de 1979, a política de filho único, ou seja, a política neomalthusiana mais draconiana da história. Os Estados Unidos, por outro lado, sob a liderança do governo neoliberal de Ronald Reagan, abandonaram a defesa do controle da natalidade e passaram a defender o laissez-faire populacional. 0 assessor do governo Reagan, Julian Simon, desenvolveu uma ampla atividade em defesa 
da dinâmica demográfica com base em princípios conhecidos como "fundamentalismo de mercado” e na relação positiva entre população e desenvolvimento. A Conferência de 1984 seria também marcada por uma nova inflexão política: o ressurgimento do conservadorismo moral no trato das questões populacionais (ALVES; CORRÊA, 2003).

Este breve panorama das Conferências de Bucareste e do México mostra que a questão demográfica foi objeto de disputa e as posições ideológicas variaram bastante no espaço de dez anos, com alternância de visões: se a população seria uma variável dependente, independente ou neutra. Desta forma, não parece tão simples afirmar que: “Nas conferências, a população sempre foi vista como um 'problema', numa perspectiva “antipopulação”” (CAMARANO, 2013, p. 604). Numa visão oposta, para May (2012, p. 110), "Consensus-building through international conferences and their preparatory meetings is often inefficient as a process". Na realidade, os defensores da expansão do capital e do consumo, o dogmatismo religioso e as forças familistas e do conservadorismo moral (como o Partido Republicano e o Tea Party nos Estados Unidos) sempre defenderam a perspectiva pró-população.

Também não houve uma posição “antipopulação” na Conferência de 1994. A CIPD do Cairo ocorreu após o fim da Guerra Fria e foi a primeira a incorporar a palavra desenvolvimento no seu título. Ela também incluiu os princípios da Conferência das Nações Unidas sobre Desenvolvimento Sustentável, conhecida como Rio-92, apontando a necessidade de os países adotarem políticas públicas no sentido de promover o "crescimento econômico sustentado no contexto de um desenvolvimento sustentável”. Se o consenso do Cairo apontou a necessidade da estabilização do crescimento da população mundial, isto se deu por razões evidentes de que não é possível haver crescimento infinito em um mundo finito, mas a CIPD não marcou data e nem criou os meios para efetivar tal objetivo.

O ponto forte da CIPD do Cairo foi a defesa dos direitos humanos e dos direitos reprodutivos. No capítulo II do Programa de Ação estão explicitados os 15 princípios gerais da Conferência. 0 princípio 1 reafirma os compromissos da Declaração Universal dos Direitos Humanos de 1948. O princípio 2 diz que o ser humano é o elemento central do desenvolvimento sustentável e tem o direito a uma vida sã e produtiva em harmonia com a natureza, sendo que toda pessoa tem o direito a um nível de vida adequado para si e sua família.

O princípio 3 considera que o desenvolvimento é um direito universal e visa satisfazer equitativamente as necessidades ambientais das gerações presentes e futuras. Os demais princípios englobam: equidade de gênero; combate aos padrões insustentáveis de produção e consumo; erradicação da pobreza; acesso universal a serviços de saúde, incluindo os relacionados com a saúde reprodutiva; proteção às diversas formas de família; defesa do casamento contraído com o livre consentimento dos cônjuges; direito à educação voltada para o fortalecimento da dignidade humana; defesa dos direitos das crianças; defesa dos direitos dos imigrantes e dos refugiados; apoio aos povos indígenas; e defesa da cooperação internacional, reconhecendo as responsabilidades comuns, mas diferenciadas entre os países. 
Buscando superar o embate entre "controlistas" e "natalistas”, a CIPD definiu os direitos reprodutivos como sendo a liberdade de escolha das pessoas para definir como, quando e quantos filhos querem ter (incluindo o direito à fecundidade zero, evitando a maternidade forçada). Neste sentido, parece um equívoco considerar que o consenso do Cairo representou uma defesa dos "direitos não reprodutivos" (CAMARANO, 2013, p. 604). Na verdade, a Conferência do Cairo defendeu o direito à concepção e à contracepção, ficando a cargo dos cidadãos e cidadãs decidir, livremente, sobre as opções de escolha.

\section{A dinâmica demográfica global e o desenvolvimento (in)sustentável}

A despeito das boas intenções das conferências de população, desenvolvimento e meio ambiente, as atividades antrópicas continuam degradando a natureza, sem uma solução concreta para evitar o colapso ambiental, tema que passou a ser a questão mais sensível e urgente da atualidade.

O século XX apresentou o maior crescimento demográfico de toda a história da humanidade, com a população mundial aumentando quase quatro vezes (de cerca de 1,6 bilhão de habitantes em 1900 para 6 bilhões em 2000). Mas a taxa de fecundidade total (TFT), que estava em torno de 5 filhos por mulher em meados do século, começou a cair a partir de 1965 e chegou a 2,53 filhos na virada do milênio. Desta forma, o ritmo de crescimento demográfico vai diminuir no século XXI, embora deva continuar positivo, pois existe uma certa estagnação da transição da fecundidade. A queda da fecundidade mundial foi de 31,5\% nos 20 anos anteriores à CIPD de 1994 e de 18\% nos 20 anos posteriores. A Divisão de População da ONU, na revisão 2012, estima uma TFT global de 2,24 filhos por mulher, no quinquênio 2045-50, e de 2,0 filhos por mulher, no quinquênio 2095-2100. Portanto, a estabilização da população mundial só seria alcançada, caso seja, no início do século XXII.

Desta forma, parece intempestiva a afirmação: "Mesmo que a fecundidade aumente em um futuro próximo, é improvável que o declínio populacional seja abortado" (CAMARANO, 2013, p. 606). Ao contrário, a projeção média da ONU estima uma população mundial de 10,9 bilhões de habitantes em 2100, um acréscimo de 4,8 bilhões de habitantes no século XXI, quantidade superior, em termos absolutos, aos 4,5 bilhões do século XX. Boa parte do atual crescimento populacional é inercial e seria equivocado reforçar os argumentos dos alarmistas da superpopulação. Contudo, colocar em pauta a iminência do declínio da população mundial como se fosse uma ameaça de colapso da espécie humana ignora o verdadeiro perigo que é o círculo infernal que se abate sobre milhares de outras espécies que estão sendo extintas e os ecossistemas que estão sendo desconfigurados.

Dizer que a redução da população vai prejudicar o crescimento econômico é desconsiderar que, do ponto de vista mais amplo da sobrevivência da vida no Planeta, o desenvolvimento tem se tornado o problema central. Pouco adiantou a CIPD ter incorporado os princípios da Cúpula da Terra (Rio-92), acrescentando o substantivo sustentável ao 
desenvolvimento. Também foi um fiasco a ideia de economia verde, apresentada na Rio+20, em 2012, pois, na prática, a economia verde e o desenvolvimento sustentável viraram maquiagem verde (greenwashing), sem perspectivas de conter o regresso ambiental. Ao garantir dignidade e direitos exclusivamente aos seres humanos, o modelo egocêntrico de desenvolvimento incorre, frequentemente, nos crimes do especismo e do ecocídio. Porém, a natureza deveria ser respeitada por seu valor intrínseco e não pelos benefícios utilitaristas que fundamentam os padrões insustentáveis de produção e consumo (GUDYNAS, 2010; ALVES, 2014a).

O Living Planet report (WWF, 2012) mostra que a pegada ecológica da população mundial já superava em 50\% a biocapacidade do Planeta, em 2008. Ou, dito de outra forma, a humanidade estava gastando em um ano o que a capacidade regenerativa da natureza consegue repor em um ano e meio. Outra metodologia que indica que as atividades antrópicas estão ultrapassando os limites da Terra é conhecida como Fronteiras Planetárias. Johan Rockström, da Universidade de Estocolmo, e colegas (ROCKSTRÖM et al., 2009) identificaram nove dimensões centrais para a manutenção de condições de vida decentes para as sociedades humanas e o meio ambiente: mudanças climáticas; perda de biodiversidade; uso global de água doce; acidificação dos oceanos; mudança no uso da terra; depleção da camada de ozônio estratosférico; ciclo do nitrogênio e fósforo; concentração de aerossóis atmosféricos; e poluição química. Por exemplo, em 2013, a concentração de $\mathrm{CO}_{2}$ na atmosfera ultrapassou 400 partes por milhão (ppm), bem acima das 280 ppm da era pré-industrial. 0 limiar de segurança é de 350 ppm.

Está em xeque o modelo que traz muitos benefícios para poucos, poucos benefícios para muitos e nenhum benefício para a natureza e a biodiversidade. Porém, o crescimento econômico tem sido uma aspiração não só das forças capitalistas, mas também dos trabalhadores e dos governos. O capitalismo usa o crescimento populacional como "combustivel" que amplia a força de trabalho e cria gerações sucessivas de consumidores, como pode ser confirmado nesta citação do documento Visão 2050, do Conselho Empresarial Mundial para o Desenvolvimento Sustentável (WBCSD): “Em apenas 40 anos, nosso planeta terá um acréscimo de cerca de 30\% em seu número de habitantes. Para o mundo corporativo, isso certamente representa bilhões de novos consumidores ávidos por casas, carros e aparelhos de TV" (CEBDS, 2009).

Neste sentido, não há como discordar quando Ana Amélia diz: "Acredita-se que nenhum país deseje o declínio populacional, pois isto tem implicações de várias ordens. A primeira é a perda de poder econômico e geopolítico em relação a países onde a população ainda cresce" (CAMARANO, 2013, p. 606). Mas a autora parece cair em contradição ao considerar que a população não é um problema quando há crescimento, mas se torna um problema quando há decrescimento.

Realmente, o declínio da população e da economia é um anátema do capitalismo. 0 desejo de acumulação de riqueza pessoal e nacional, os interesses geoestratégicos do poder político e as diversas forças pró-natalistas do mundo somam-se para manter por mais tempo 
possível o processo de ampliação do desenvolvimento econômico. O economista inglês John Stuart Mill já havia escrito, em 1848, que o crescimento ilimitado da economia e da população seria uma impossibilidade histórica e que o “Estado estacionário”, para o bem da natureza, iria predominar, cedo ou tarde (MILL, 1983). Em termos demográficos, Striessnig e Lutz (2014) consideram que uma taxa de fecundidade abaixo do nível de reposição, entre 1,5 e 1,8 filho por mulher, seria a mais adequada para uma estrutura etária favorável à preservação do planeta e ao aumento do bem-estar da população global.

A escola da economia ecológica há muito argumenta que "A economia é um subsistema do ecossistema, e o ecossistema é finito, não cresce e é materialmente fechado", como afirmou Herman Daly, que também considera que o desenvolvimento atual tem gerado um "crescimento deseconômico", com os custos sendo maiores do que os benefícios. Ele completa: "Precisamos decrescer até chegar a uma escala sustentável que, então, procuramos manter num estado estacionário. O decrescimento, assim como o crescimento, não pode ser um processo permanente" (IHU, 2011).

Sem dúvida, tem aumentado o número de pessoas que consideram o desenvolvimento o principal vetor de destruição das fontes naturais da vida e da biodiversidade. 0 capitalismo não consegue ser ao mesmo tempo socialmente inclusivo, justo e ambientalmente sustentável. Por conta disto, alguns autores falam em desenvolvimento sem crescimento, como Tim Jackson no livro Prosperity without growth? The transition to a sustainable economy, enquanto outros defendem a ideia do decrescimento (LATOUCHE, 2009; DEMARIA et al., 2013; MEDIAVILLA, 2013; ALVES, 2014b). Pouco antes da Rio+20, em 2012, a revista Estudos Avançados da USP publicou um número com diversos artigos tratando dos limites do crescimento econômico e a possibilidade do decrescimento.

\section{Desenvolvimento sustentável ou sustentabilidade ecocêntrica?}

Os dados dos últimos dois séculos mostram que Malthus estava errado, pois, se a população mundial passou de 1 bilhão de habitantes em 1800 para 7 bilhões em 2011, um crescimento de sete vezes, no mesmo período a economia internacional cresceu 90 vezes e a renda per capita aumentou 13 vezes, possibilitando, a despeito das desigualdades, uma redução da pobreza e a elevação do nível de consumo da população mundial (MADDISON, 2010).

Porém, a maior parte do crescimento demoeconômico ocorrido no século XX só foi possível por uma incrível conjugação de forças favoráveis: grande disponibilidade de energia fóssil a preços muito baixos; elevada disponibilidade de recursos naturais (terra, água, florestas, biodiversidade, etc.); grande aumento da esperança de vida e dos anos médios dedicados às atividades produtivas; estrutura etária favorável com aumento da parcela de "produtores" sobre os "consumidores"; ampliação dos níveis educacionais e do capital humano; aumento do estoque de capital fixo; elevação do progresso técnico; crescimento da produtividade dos fatores de produção; estabilidade do clima; e condições favoráveis do meio ambiente. 
Olhando para o futuro, no entanto, há fortes razões para duvidar que o ritmo histórico de crescimento possa ser mantido. O pesquisador americano Robert Gordon (2012) considera que o alto crescimento econômico do passado não vai mais se repetir, devido aos ventos contrários que tendem a criar uma "estagnação secular". Tverberg (2014) prevê uma crise financeira mundial em decorrência do alto preço de extração dos combustíveis fósseis e outros recursos minerais e da "bolha de carbono". O processo de acumulação capitalista, além de suas contradições internas, já ultrapassou a capacidade de carga do Planeta e caminha para um impasse, pois a cadeia produtiva aprisiona e degrada os recursos da Terra, enquanto a desigualdade de renda agrava a exclusão social (MOTESHARREI et al., 2014).

A ideia do desenvolvimento sustentável virou um mito tecnocrático. Como afirmou Martine (2014, p. 214), “As perspectivas para o 'desenvolvimento sustentável’ têm minguado drasticamente desde a Conferência do Cairo devido, justamente, à propagação global e ao sucesso de um paradigma de desenvolvimento baseado em um crescimento econômico chamado de throughput growth". Os governos e as empresas usam o termo "desenvolvimento sustentável" para vender a ideia de que é possivel manter o ritmo atual do modelo de produção e consumo de energia, bens e serviços, desde que gerem lucros e receitas fiscais. Mas a crença cega no progresso tecnológico como panaceia social e ambiental tem se tornado uma ficção científica.

O modelo atual de desenvolvimento é insustentável tanto em termos ambientais quanto sociais. 0 alto crescimento econômico dos últimos 200 anos reduziu a pobreza absoluta, mas não foi capaz de garantir o mínimo de justiça na distribuição da riqueza. De acordo com a Oxfam (2014), as 85 pessoas mais ricas do globo têm propriedades no valor de US\$1,7 trilhão, o que equivale ao patrimônio das 3,5 bilhões de pessoas mais pobres do mundo, sendo que a riqueza do 1\% dos mais ricos equivale a um total de US\$ 110 trilhões, 65 vezes a riqueza da metade mais pobre da população e quase metade da riqueza total do Planeta.

O crescimento das atividades antrópicas tornou dramática a insustentabilidade ambiental. As áreas de florestas estão diminuindo para atender à demanda de madeira e espaço para a agropecuária. Espécies invasoras substituem a vegetação original. O mal uso do solo provoca erosão, salinização e desertificação. A contaminação química, os fertilizantes nitrogenados e os agrotóxicos matam indiscriminadamente a vida terrestre e aquática. Aquíferos fósseis estão desaparecendo e os renováveis não estão conseguindo manter os níveis de reposição de carga, provocando estresse hídrico. A vida nos oceanos está ameaçada pelo processo de acidificação. Os mangues e corais estão sendo destruídos de forma alarmante. A poluição dos rios, que espalha as toxinas de cianobactérias, diminui a disponibilidade de água doce e provoca a mortandade de peixes e da vida aquática. Lagos, como o mar de Aral, estão diminuindo ou secando para atender aos interesses da irrigação para alimentar uma população crescente. Aumentam a taxa de extinção de espécies e a degradação dos ecossistemas, com redução da vida selvagem. As áreas produtivas diminuem, enquanto crescem os aterros de descarte antrópico. O aumento das emissões de gases de efeito estufa está acelerando o aquecimento global, derretendo o gelo dos polos e das geleiras e 
provocando escassez de água potável e elevação do nível dos oceanos. Os eventos climáticos extremos provocam prejuízos econômicos e a perda de vida humana e não humana (UNEP, 2012; BECKER, 2013).

O Consenso de Montevidéu - documento aprovado na 1a CRPD da América Latina e Caribe - diz, de forma bastante apropriada, que é preciso garantir um equilíbrio harmonioso e dinâmico entre o desenvolvimento sustentável e a saúde da biodiversidade e dos ecossistemas. Porém, o documento final da 47a Reunião da Comissão de População e Desenvolvimento (CPD) da ONU, realizada de 7 a 11 de abril de 2014, fez uma defesa contundente do desenvolvimento e do crescimento econômico, sem estabelecer qualquer condicionante ao processo de acumulação de lucro e depleção da natureza. A CPD/2014 sequer repetiu as passagens do Programa de Ação da CIPD/1994 que condenou "a degradação ambiental levada a efeito por sistemas não-sustentáveis de produção e consumo" (ALVES, 2014c).

Em vez de defender o crescimento econômico sem limites, seria conveniente introduzir na agenda internacional o debate sobre o conceito de decrescimento demoeconômico, que deveria ocorrer juntamente com as mudanças no padrão de consumo e na distribuição funcional da renda produtiva. Não há direitos humanos duradouros sem direitos da natureza. As concepções antropocêntricas do desenvolvimento concentrador da riqueza precisam abrir espaço para o reconhecimento de que a economia faz parte da ecologia e que as desigualdades extremas são incompatíveis com a justiça e a paz social. Diante da possibilidade de um colapso ambiental, as atividades humanas deveriam ser direcionadas para a recuperação ecológica e não para a acumulação da riqueza ostentatória em benefício de uma minoritária elite populacional. Estas deveriam ser algumas das perspectivas a serem consideradas na CIPD pós-2014 e no processo de definição dos Objetivos do Desenvolvimento Sustentável (ODS).

\section{Referências}

ALVES, J. E. D.; CORRÊA, S. Demografia e ideologia: trajetos históricos e os desafios do Cairo + 10. Revista Brasileira de Estudos de População, v. 20, n. 2, jul./dez. 2003.

ALVES, J. E. D. Do antropocentrismo ao ecocentrismo: uma mudança de paradigma. In: MARTINE, G. (Ed.). População e sustentabilidade na era das mudanças ambientais globais: contribuições para uma agenda brasileira. Belo Horizonte: Abep, 2012. n. 49, 2014a.

O decálogo da sustentabilidade ecocêntrica. Revista Cidadania \& Meio Ambiente, Sustentabilidade, aquecimento global e o decrescimento demo-econômico, Diamantina. Revista Espinhaço, v. 3, n. 1, 2014 b.

As limitações da ONU: CPD versus IPCC. Ecodebate, Rio de Janeiro, 16/04/2014C.

BECKER, S. Has the world really survived the population bomb? Demography, v. 50, n. 6, p. 2173-2181, Dec. 2013,

BERQUÓ, E. As posições da OMS nas conferências de população da ONU nos últimos 50 anos. 
In: WONG, L. R. et al. Cairo+20: perspectivas de la agenda de población y desarrollo sostenible después de 2014. Rio de Janeiro, Alap, 2014, p. 17-22.

CALDWELL, J. C. Theory of fertility decline. London: Academic, 1982.

CAMARANO, A. A. Perspectivas para o Cairo+20: como avançar na discussão sobre população e desenvolvimento. Revista Brasileira de Estudos de População, v. 30, n. 2, p. 603-608, 2013.

CEBDS. Visão 2050: a nova agenda para as empresas. São Paulo: Conselho Empresarial Brasileiro para o Desenvolvimento Sustentável, 2009.

COALE, A.; HOOVER, E. População e desenvolvimento econômico. Rio de Janeiro: Fundo de Cultura, 1966.

COALE, A. The demographic transition: a summary, some lessons and some observations. In: CHO, L.; KOBAYASHI, K. (Eds.). Fertility transition of East Asian populations. Honolulu: U. Press of Hawaii, 1979.

COHEN, J. Malthus Miffed: are people the problem, the solution, or both? The Floating University, 2012. DEMARIA, F. et al. What is degrowth? From an activist slogan to a social movement. Environmental Values, v. 22, n. 2, p. 191-215, 2013.

GORDON, R. J. Is US economic growth over? Faltering innovation confronts the six headwinds. Cambridge, Massachusetts: NBER, August 2012 (Working paper, 18315).

GUDYNAS, E. La senda biocéntrica: valores intrínsecos, derechos de la naturaleza y justicia ecológica. Tabula Rasa, n. 13, p. 45-71, julio-diciembre 2010.

IHU - Instituto Humanitas Unisinos. Guru da economia ecológica defende decrescimento. São Leopoldo, IHU, 2011. Disponivel em: 〈http://www.ihu.unisinos.br/noticias/46669-guru-da-economia-ecologicadefende-decrescimento〉.

LATOUCHE, S. Pequeno tratado do decrescimento sereno. São Paulo: WMF Martins Fontes, 2009.

MADDISON, A. Historical statistics of the world economy. 2010 (site do autor).

MARTINE, G. O contraste entre o desenvolvimento sustentável na CIPD e a realidade atual. In: WONG, L. R. et al. Cairo+20: perspectivas de la agenda de población y desarrollo sostenible después de 2014 . Rio de Janeiro: Alap, 2014, p. 213-224.

MAY, J. F. World population policies: their origin, evolution, and impact. Dordrecht: Springer, 2012.

MEDIAVILLA, M. Retos globales ante los límites al crecimiento. Grupo de Energía y Dinámica de Sistemas - Universidad de Valladolid, 22 de septiembre de 2013.

MILL, J. S. Princípios de economia política. São Paulo: Abril Cultural, 1983.

MOTESHARREI, S. et al. Human and nature dynamics (HANDY): modeling inequality and use of resources in the collapse or sustainability of societies. Journal Ecological Economics, March 19, 2014.

NOTESTEIN, F. Population: the long view. In: SCHULTZ, T. W. (Ed.). Food for the world. Chicago: Universit of Chicago Press, 1945.

OXFAM. Working for the few: political capture and economic inequality. Oxfam Briefing Paper, 20/01/2014.

RAWORTH, K. Um espaço seguro e justo para a humanidade. Podemos viver dentro de um "Donut"? Oxfam, fevereiro de 2012 (Textos para discussão).

ROCKSTRÖM, J. et al. A safe operating space for humanity. Nature, n. 461, September 24, 2009.

STRIESSNIG, E.; LUTZ, W. How does education change the relationship between fertility and 
age-dependency under environmental constraints? A long-term simulation exercise. Demographic Research, v. 30, article 16, p. 465-492, February 20, 2014.

SMITH, A. A riqueza das nações. São Paulo: Abril Cultural, 1983.

JACKSON, T. Prosperity without growth? The transition to a sustainable economy. Earthscan/Routledge, 2009

TVERBERG, G. A forecast of our energy future: why common solutions don't work. Blog, 29/01/2014.

UNEP. Global Environment Outlook-5: environment for the future we want (GEO-5). 2012.

UNSDSN. An action agenda for sustainable development. New York, 21/10/2013.

WWF. Living Planet report: biodiversity, biocapacity and better choices. WWF, 2012.

\section{Autor}

José Eustáquio Diniz Alves é doutor em demografia pelo Cedeplar/UFMG, com pós-doutorado no Nepo/ Unicamp, professor titular do Programa de Pós-graduação em População, Território e Estatísticas Públicas da Escola Nacional de Ciências Estatísticas - Ence, do Instituto Brasileiro de Geografia e Estatística - IBGE.

\section{Endereço de correspondência}

José Eustáquio Diniz Alves

Rua André Cavalcanti, 106, sala 502, Bairro de Fátima

Rio de Janeiro, RJ - CEP 20231-050

Recebido para publicação em 11/12/2013

Aceito para publicação em 02/02/2014 